\title{
Addition of dexmedetomidine to epidural morphine to improve anesthesia and analgesia for cesarean section
}

\author{
YICHEN YANG $^{1 *}$, CHENGJUN SONG $^{2 *}$, CHENGWEI SONG ${ }^{2}$ and CHENGWEN LI $^{3}$ \\ ${ }^{1}$ Department of Anesthesiology, Zoucheng People's Hospital, Zoucheng, Shandong 273500; ${ }^{2}$ Department of Anesthesiology, \\ Jining No. 1 People's Hospital, Jining Medical University, Jining, Shandong 272011; ${ }^{3}$ Department of Anesthesiology, \\ Beijing Friendship Hospital, Capital Medical University, Beijing 100050, P.R. China
}

Received April 24,2019; Accepted November 13, 2019

DOI: $10.3892 /$ etm.2020.8429

\begin{abstract}
The aim of the present study was to evaluate the effectiveness and safety of the combination of epidural dexmedetomidine and morphine in providing anesthesia during cesarean surgery and analgesia for post-cesarean pain relief when added to epidural ropivacaine. A total of 80 females at term scheduled for elective cesarean delivery were randomly assigned to two groups (n=40/group): In the morphine group (group M), patients received an epidural injection of $0.75 \%$ ropivacaine $(12 \mathrm{ml})$ and morphine $(2 \mathrm{mg})$ for surgical anesthesia, and epidural infusion of morphine $(2 \mathrm{mg})$ in $100 \mathrm{ml}$ $0.2 \%$ ropivacaine at $2 \mathrm{ml} / \mathrm{h}$ for 48 -h post-operative analgesia; and in the morphine combined with dexmedetomidine group (group DM), patients received an epidural injection of $0.75 \%$ ropivacaine $(12 \mathrm{ml})$ and morphine $(2 \mathrm{mg})$ combined with dexmedetomidine $(0.5 \mu \mathrm{g} / \mathrm{kg})$ for surgical anesthesia, and epidural infusion of morphine $(2 \mathrm{mg})$ and dexmedetomidine $(200 \mu \mathrm{g})$ in $100 \mathrm{ml} 0.2 \%$ ropivacaine at $2 \mathrm{ml} / \mathrm{h}$ for $48-\mathrm{h}$ post-operative analgesia. The primary outcomes included blockade and analgesic effects, sedation and adverse reactions associated with the drugs. Neonatal outcome was also assessed by determining the Apgar score and umbilical cord blood analysis. There was no significant difference between the groups in the cephalad levels of sensory blockade at 20 min post-injection, or in muscle relaxation scores or pain intensity scores at rest or upon movement at $4,12,24$ or $48 \mathrm{~h}$ post-injection $(\mathrm{P}>0.05)$. The maternal patients in the DM group experienced more complete motor blockade at $20 \mathrm{~min}$ post-injection, better sedation during surgery and following delivery, and less visceral pain caused by peritoneal traction
\end{abstract}

Correspondence to: Dr Chengwen Li, Department of Anesthesiology, Beijing Friendship Hospital, Capital Medical University, 95 Yongan Road, Xicheng, Beijing 100050, P.R. China

E-mail: lichwen2008@126.com

*Contributed equally

Key words: epidural anesthesia, cesarean section, dexmedetomidine, morphine, adverse reactions during surgery and by uterine contraction after delivery, compared with those in group $\mathrm{M}(\mathrm{P}<0.05)$. The patients in group $\mathrm{M}$ had a lower incidence and severity score of post-operative nausea than those in the DM group $(\mathrm{P}<0.05)$. There was no significant difference between the groups in terms of Apgar score or umbilical cord blood gas values $(\mathrm{P}>0.05)$. In conclusion, epidural dexmedetomidine reduces intra-operative and post-operative visceral pain and produces better sedation during surgery and following delivery, without any significant influence on morphine-associated side effects and post-operative analgesia, in females undergoing elective cesarean section under epidural anesthesia with morphine and ropivacaine (registration number ChiCTR1900027942; retrospectively registered with the Chinese Clinical Registry Center on December 6, 2019).

\section{Introduction}

Cesarean section is commonly performed under neuraxial anesthesia in the absence of contraindications and medical emergency. The major disadvantages of routine epidural anesthesia for cesarean section include the delayed onset of surgical anesthesia, inadequate blockade for preventing visceral pain and insufficient muscle relaxation (1). To overcome these defects, co-administration of local anesthetics with adjuvant drugs has become a widely accepted practice in the clinic (2). The combination of epidural opioids with local anesthetics is a well-known drug formula for cesarean section and subsequent post-cesarean analgesia (3). Epidural opioids may enhance the sensory and motor blockade of epidural local anesthetics and decrease the requirement for local anesthetics for post-cesarean analgesia. Even a single dose of epidural morphine provides excellent prolonged pain relief (4). Epidural morphine (4 mg) is recommended for analgesia following cesarean delivery with an acceptable side effect profile (5). However, adverse events associated with epidural morphine, including nausea, vomiting and pruritus, still frequently occur (5).

Dexmedetomidine is a more selective $\alpha 2$ adrenergic agonist when compared with clonidine (6). The two agents mediate their analgesic effect by stimulating the $\alpha 2$ receptor located post-synaptically on the dorsal horn of the spinal cord (6). A recent systematic meta-analysis demonstrated that dexmedetomidine as an adjuvant in epidural 
anesthesia provided improved sedation and analgesia with a well-documented safety profile (7). Several studies involving epidural dexmedetomidine in obstetric populations have been published: Dexmedetomidine added to combined spinal (bupivacaine)-epidural (fentanyl) anesthesia for cesarean section $(1,2)$; combined epidural dexmedetomidine and ropivacaine for post-cesarean analgesia (8); and epidural dexmedetomidine combined with ropivacaine or bupivacaine for labor analgesia (9-12). All these previous studies demonstrated the potentiating effect of epidural dexmedetomidine on neuraxial analgesia, with minimal side effects (1,2,8-12).

Clonidine has been used as an adjuvant to epidural morphine and bupivacaine, and this supplement enhances post-operative analgesia after cesarean delivery (13). It was hypothesized that, when used in combination with a relatively low dose of epidural morphine for cesarean section, dexmedetomidine may potentiate the anti-nociceptive effect of morphine without any additional adverse reactions. The present study investigated the effectiveness and safety of the combination of epidural dexmedetomidine and morphine in anesthesia for cesarean surgery and in analgesia for post-cesarean pain relief, when added to epidural ropivacaine.

\section{Materials and methods}

Subjects and group allocation. The present study was approved by the Jining No. 1 People's Hospital Ethics Committee for Human Studies (Jining, China) and written informed consent was obtained from all patients. A total of 90 females with an American Society of Anesthesiologists physical status of I or II and with full-term gestational singleton pregnancies, scheduled to undergo elective cesarean delivery, were enrolled in the present study. The patients were recruited between July 2018 and December 2018. Exclusion criteria included absolute or relative contraindications to neuraxial anesthesia, a history of substance abuse, allergy to the drugs involved in the study and known fetal abnormalities.

Prior to the start of the study, patients were randomly assigned, through a computer-generated random number list with assigned numbers sealed in envelopes, to the morphine group (group M) or to the morphine combined with dexmedetomidine group (group DM). Study drugs were prepared by a nurse anesthetist who was not involved in the care or assessment of the patients. The patients and the other members of the research team were unaware of the group allocations.

Anesthetic and analgesic procedure. At one day prior to the surgery, during interview, the patients were instructed on the use of a 0-10 numeric rating scale (NRS) for pain intensity and a 4-point ordinal verbal rating scale for pruritus, nausea, vomiting and dizziness.

After the establishment of intravenous access and standard monitors in the operating theatre, the patients were placed in the left lateral position and lumbar spine vertebral spaces 1-3 were identified. The preferred insertion site was the L2-3 interspace. However, if it was impossible to introduce the needle at the selected site, the L1-2 interspace was used instead. Under strict aseptic conditions, the skin at the insertion site was infiltrated with $1 \%$ lidocaine $(2 \mathrm{ml})$. A Tuohy $18 \mathrm{G}$ epidural needle was introduced using the midline approach and the loss of resistance technique, and the epidural catheter was threaded 3-4 cm cephalad into the epidural space through the needle. A test dose of $2 \%$ lidocaine $(3 \mathrm{ml})$ with adrenaline $(1: 200,000)$ was injected via the catheter to detect intrathecal or intravascular misplacement. A period of $3 \mathrm{~min}$ later, $12 \mathrm{ml}$ of a $0.75 \%$ ropivacaine solution with morphine $(2 \mathrm{mg})$, combined with dexmedetomidine $(0.5 \mu \mathrm{g} / \mathrm{kg}$; group DM) or without dexmedetomidine (group M), was intermittently injected via the catheter. At $20 \mathrm{~min}$ after the injection, the maximum cephalad level of sensory block was identified through a pinprick and the surgery was started. If general anesthesia was given due to failed epidural anesthesia, the patient was excluded from the present study. After fetal delivery, if the NRS score was $>3$, sufentanil $(10 \mu \mathrm{g})$ was intravenously administered. At the end of surgery, a patient-controlled epidural analgesia (PCEA) device was attached to the epidural catheter for 48-h post-operative analgesia, with morphine $(2 \mathrm{mg})$ combined with dexmedetomidine (200 $\mu \mathrm{g}$; group DM) or without dexmedetomidine (group M) in $100 \mathrm{ml}$ of $0.2 \%$ ropivacaine at a background infusion of $2 \mathrm{ml} / \mathrm{h}$, with a $0.5-\mathrm{ml}$ bolus dose and a 15-min lockout interval. Tramadol $(50 \mathrm{mg})$ as rescue analgesia for PCEA was given intramuscularly if the NRS score was $>3$ at rest and repeated every $6 \mathrm{~h}$ if necessary. If the PCEA was halted due to unexpected removal of the epidural catheter or other causes, the patient was also excluded from the present study.

Assessments. The primary endpoints were the characteristics of the blockade and analgesic effects, sedation and adverse reactions associated with the study drugs. The maximum cephalad level of the sensory block at $20 \mathrm{~min}$ after epidural injection was recorded. The NRS (0, no pain; 10 , worst possible pain) was used to assess the pain intensity at the point of skin incision, and at 4, 12, 24 and $48 \mathrm{~h}$ after injection at rest and upon movement (from lying in bed to sitting on the edge of the bed). Motor blockade and sedation level were assessed at the point of skin incision, the end of surgery, and 4, 12, 24 and $48 \mathrm{~h}$ after injection, using the modified Bromage scale $(0$, able to move the hip, knee and ankle; 1, unable to move the hip, but able to move the knee and ankle; 2, unable to move the hip or knee, but able to move the ankle; and 3, unable to move the hip, knee or ankle) (14) and the Ramsey sedation scale (1, anxious, agitated and restless; 2 , cooperative, oriented and tranquil; 3 , responsive to commands only; 4 , brisk response to light glabellar tap or loud auditory stimulus; 5, sluggish response to light glabellar tap or loud auditory stimulus; and 6, no response to light glabellar tap or loud auditory stimulus) (15). The time-point of first out-of-bed activity was also recorded. Visceral pain caused by lifting the uterus and/or the peritoneum during surgery, or by uterine contraction within $48 \mathrm{~h}$ after delivery, was also measured using the NRS. Muscle relaxation was assessed using a 4-point verbal rating system (1, poor; 2, fair; 3, good; 4, excellent). The incidence and severity of adverse reactions, including pruritus, nausea, vomiting and dizziness, were evaluated using a 4-point ordinal verbal rating scale ( 0 , none; 1 , mild; 2 , moderate; 3 , severe). For moderate to severe nausea or vomiting, ondansetron (4 mg) was intravenously administered every $6 \mathrm{~h}$ as required. For moderate to severe pruritus, diphenhydramine (25-50 mg) was given intravenously every $4 \mathrm{~h}$ as required. 
Secondary endpoints included adverse cardiovascular events, shivering, adverse neonatal condition and maternal neurological complications. Hypotension was defined as a systolic blood pressure $<80 \mathrm{mmHg}$ or decreasing to $\geq 30 \%$ below baseline, and was managed with intravenous fluids and phenylephrine $(0.2 \mathrm{mg})$. Bradycardia was determined as a heart rate $<50$ beats $/ \mathrm{min}$ and was managed with atropine $(0.5 \mathrm{mg})$. Shivering was measured after clamping of the umbilical cord via a 5 -point scoring system ( 0 , no visible shivering; 1 , no visible shivering, but peripheral vasoconstriction or piloerection was observed; 2, activity in one muscle group only; 3 , activity in more than one muscle group, but shivering was not generalized; 4 , shivering involving the whole body) (16). Umbilical venous and arterial blood samples were drawn from a double-clamped segment of the umbilical cord for analysis of blood gas at delivery. Apgar scores at 1 and 5 min after delivery and Neonatal Adaptive and Capacity Score (NACS) (17) at $24 \mathrm{~h}$ after delivery were also recorded. An Apgar score of $<7$ was considered abnormal. A NACS $<35$ was also considered abnormal. All patients were followed up for 2 weeks post-operatively for the detection of any sensory or motor effect.

Statistical analysis. Statistical analysis of the data was performed with SPSS (version 13.0; SPSS Inc.). The normality of the distribution was determined using the Kolmogorov-Smirnov test. The values are expressed as the mean \pm standard deviation for quantitative variables (age, weight, height, gestational age, surgical time, skin incision-to-delivery interval, infusion volume, the values of umbilical blood gas analysis and NACS score), as n (\%) for categorical variables (comorbidity, insertion site, and remedial sufentanil during surgery, remedial tramadol after surgery, and the number of patients with each adverse reaction or cardiovascular event) and as the median (interquartile range) for ordinal variables (maximum cephalad level of the sensory block at 20 min after injection, the scores of pain severity, motor block, sedation and muscle relaxation, and Apgar scores). Quantitative variables were compared using unpaired Student's t-tests. Ordinal variables were compared using a Mann-Whitney U-test and categorical variables were compared using a $\chi^{2}$ test or Fisher's exact test. $\mathrm{P}<0.05$ was considered to indicate a statistically significant difference.

Sample size analysis. According to a pilot study performed prior to initiating the formal study, sufentanil was required for alleviating the visceral pain caused by peritoneal traction in 6/10 patients who received a combination of epidural morphine and ropivacaine. It was assumed that the addition of epidural dexmedetomidine would lead to a $50 \%$ decrease in the number of cases requiring remedial sufentanil for visceral pain relief; at least 34 patients were required in each group for a power of 0.8 and a type one error of 0.05 . Therefore, 45 patients were selected per group to account for unexpected bias.

\section{Results}

Patient demographics and surgical characteristics. A total of 10 patients did not complete the study due to patient refusal (4 per group), failed epidural anesthesia (1 in group DM) or unexpected removal of the epidural catheter (1 in group $\mathrm{M})$.
The demographic and surgical data (Table I) were comparable in terms of age, height, weight, gestational age, surgical time and the time interval from skin incision to fetal delivery between the groups $(\mathrm{P}>0.05)$; the volume of liquid infusion was higher in group DM than that in group $\mathrm{M}(\mathrm{P}<0.05$; Table I).

Epidural blockade characteristics. There was no difference between the groups regarding the levels of the insert site, the cephalad levels of sensory block, NRS scores at the point of skin incision and muscle relaxation scores ( $P>0.05$; Table II). The Bromage motor blockade score was higher in group DM than that in group $\mathrm{M}$ at the point of skin incision (20 min after the injection; $\mathrm{P}<0.05$ ), but the scores for motor blockade in the two groups were similar at the end of surgery, and at 4, 12, 24 and $48 \mathrm{~h}$ after injection ( $\mathrm{P}>0.05$; Table II). The incidence of visceral pain caused by peritoneal traction was $70 \%$ in group $\mathrm{M}$, which was higher than the $47.5 \%$ in group DM $(\mathrm{P}<0.05)$. The number of patients who administered remedial sufentanil during surgery was higher in group $\mathrm{M}$ than that in group $\mathrm{DM}(\mathrm{P}<0.05$; Table II).

Sedation levels. On the Ramsey sedation scale, the score of the sedation level was comparable at skin incision, and at 24 and $48 \mathrm{~h}$ after injection between the groups $(\mathrm{P}>0.05)$, but the score was lower at the end of surgery, and at 4 and $12 \mathrm{~h}$ after injection, in group DM compared with that in group $\mathrm{M}(\mathrm{P}<0.05$; Table III).

Adverse effects. There was no difference between the groups regarding any adverse event occurring during or after surgery ( $P>0.05)$, except post-operative nausea, which occurred more frequently in group DM $(\mathrm{P}<0.05)$. Patients in group DM had a higher post-operative nausea score than those in group $\mathrm{M}$ $(\mathrm{P}<0.05$; Table IV).

Post-operative NRS pain scores and analgesia management. At 4, 12, 24 and $48 \mathrm{~h}$ after injection, no significant differences in NRS scores of pain intensity at rest or upon movement between the groups were detected $(\mathrm{P}>0.05)$. The number of patients who used tramadol as rescue analgesia was similar in the two groups $(\mathrm{P}>0.05)$. The number of patients experiencing visceral pain caused by uterine contraction during the 48 -h study period was lower in group DM than that in group $M$ $(\mathrm{P}<0.05)$. Furthermore, patients in group DM had a lower NRS score for visceral pain caused by uterine contraction than those in group $\mathrm{M}(\mathrm{P}<0.05$; Table $\mathrm{V})$.

Neonatal outcomes and maternal follow-up. In group DM, no umbilical blood sample was obtained from one of the patients. There was no significant difference between groups regarding the Apgar score at 1 or $5 \mathrm{~min}$, the $\mathrm{pH}, \mathrm{pCO}_{2}, \mathrm{pO}_{2}$ or base excess of umbilical venous or arterial blood, or the NACS score at $24 \mathrm{~h}$ after delivery $(\mathrm{P}>0.05$; Table VI). None of the newborns had an Apgar score $<7$ or a NACS score $<35$. No sensory or motor defects were detected in the mothers during the 2-week follow-up.

\section{Discussion}

The present study indicated that dexmedetomidine added to epidural morphine alleviated the visceral pain caused by 
Table I. Patients' characteristics and surgical data.

\begin{tabular}{|c|c|c|c|}
\hline Item & Group M (n=40) & Group DM (n=40) & P-value \\
\hline Age (years) & $31.7 \pm 4.0$ & $30.6 \pm 4.3$ & 0.238 \\
\hline Body weight before birth(kg) & $76.0 \pm 9.7$ & $74.5 \pm 10.1$ & 0.499 \\
\hline Body height $(\mathrm{cm})$ & $161.9 \pm 4.5$ & $163.6 \pm 4.8$ & 0.106 \\
\hline Gestational age (weeks) & $39.3 \pm 1.1$ & $39.5 \pm 1.2$ & 0.439 \\
\hline Secondarycesarean delivery & $16(40.0)$ & $15(37.5)$ & 0.818 \\
\hline \multicolumn{4}{|l|}{ Comorbidities } \\
\hline Primary hypertension or PIHS & $2(5.0)$ & $3(7.5)$ & 1.000 \\
\hline Diabetes mellitus or GDM & $5(12.5)$ & $4(10.0)$ & 1.000 \\
\hline Surgery time $(\mathrm{min})$ & $49.2 \pm 5.2$ & $51.3 \pm 5.8$ & 0.092 \\
\hline Skin incision-to-delivery interval (min) & $10.2 \pm 4.2$ & $10.7 \pm 4.4$ & 0.605 \\
\hline Infusion volume $(\mathrm{ml})$ & $1253 \pm 212$ & $1582 \pm 233$ & $<0.001$ \\
\hline
\end{tabular}

Values are expressed as the mean \pm standard deviation or $\mathrm{n}(\%)$. Groups: $\mathrm{M}$, patients received an epidural injection of $0.75 \%$ ropivacaine $(12 \mathrm{ml})$ and morphine $(2 \mathrm{mg})$ for surgical anesthesia, and epidural infusion of morphine $(2 \mathrm{mg})$ in $100 \mathrm{ml} 0.2 \%$ ropivacaine at $2 \mathrm{ml} / \mathrm{h}$ for 48-h post-operative analgesia; DM, patients received an epidural injection of $0.75 \%$ ropivacaine (12 ml) and morphine $(2 \mathrm{mg})$ combined with dexmedetomidine $(0.5 \mu \mathrm{g} / \mathrm{kg})$ for surgical anesthesia, and epidural infusion of morphine $(2 \mathrm{mg})$ and dexmedetomidine $(200 \mu \mathrm{g})$ in $100 \mathrm{ml} 0.2 \%$ ropivacaine at $2 \mathrm{ml} / \mathrm{h}$ for 48 -h post-operative analgesia. PIHS, pregnancy-induced hypertension syndrome; GDM, gestational diabetes mellitus .

Table II. Characteristics of epidural blockade.

\begin{tabular}{lcc}
\hline Item & Group M (n=40) & Group DM (n=40) \\
\hline Insertion site: L2-3/L1-2 & $39(97.5) / 1(2.5)$ & $40(100) / 0(0)$ \\
Maximum thoracic level of sensory block at skin incision & $6(5-8)$ & $6(4-8)$ \\
NRS score at skin incision & $0(0-0)$ & $0(0-0)$ \\
Motor block & & 0.567 \\
At skin incision & $3(2-3)$ & 0.766 \\
At the end of surgery & $3(3-3)$ & 0.035 \\
4 h after blockade & $0(0-0)$ & 0.399 \\
12 h after blockade & $0(0-0)$ & 0.192 \\
24 h after blockade & $0(0-0)$ & $0(0-1)$ \\
48 h after blockade & $0(0-0)$ & 0.317 \\
Visceral pain caused by peritoneal traction & & $0(0-0)$ \\
Cases & $28(70.0)$ & $0(0-0)$ \\
NRS scores & $5(0-7)$ & 1.000 \\
Remedial sufentanil & $26(65)$ & 1.000 \\
Muscle relaxation & $3(2-4)$ & $0(0-7)$ \\
\hline
\end{tabular}

Values are expressed as the median (interquartile range) or $\mathrm{n}(\%)$. Groups: M, patients received an epidural injection of $0.75 \%$ ropivacaine $(12 \mathrm{ml})$ and morphine $(2 \mathrm{mg})$ for surgical anesthesia, and epidural infusion of morphine $(2 \mathrm{mg})$ in $100 \mathrm{ml} 0.2 \%$ ropivacaine at $2 \mathrm{ml} / \mathrm{h} \mathrm{for} 48-\mathrm{h}$ post-operative analgesia; DM, patients received an epidural injection of $0.75 \%$ ropivacaine $(12 \mathrm{ml})$ and morphine $(2 \mathrm{mg})$ combined with dexmedetomidine $(0.5 \mu \mathrm{g} / \mathrm{kg})$ for surgical anesthesia, and epidural infusion of morphine $(2 \mathrm{mg})$ and dexmedetomidine $(200 \mu \mathrm{g})$ in $100 \mathrm{ml} 0.2 \%$ ropivacaine at $2 \mathrm{ml} / \mathrm{h}$ for 48 -h post-operative analgesia. NRS, numeric rating scale.

peritoneal traction during surgery, or by uterine contraction after surgery, and achieved better sedation. However, compared with combined epidural morphine with ropivacaine, the addition of epidural dexmedetomidine may be associated with an increasing risk of hypotension and postoperative nausea.

Epidural morphine is the gold standard for post-cesarean analgesia (18). However, it is not only associated with side effects, including nausea, vomiting, pruritus and respiratory depression, but also with an analgesic ceiling effect (19). Singh et al (20) reported that compared with two 3-mg doses of epidural morphine, two 1.5-mg doses of epidural morphine produced equivalent effects on post-cesarean pain with fewer side effects, when used as part of a multimodal analgesia regimen. Epidural morphine alone is not sufficient 
Table III. Sedation level as evaluated using the Ramsey sedation scale.

\begin{tabular}{lccc}
\hline Time-point & $\begin{array}{c}\text { Group M } \\
(\mathrm{n}=40)\end{array}$ & $\begin{array}{c}\text { Group DM } \\
(\mathrm{n}=40)\end{array}$ & P-value \\
\hline At skin incision & $1(1-2)$ & $2(1-2)$ & 0.074 \\
At the end of surgery & $2(1-2)$ & $3(2-3)$ & 0.010 \\
4 h after blockade & $2(2-3)$ & $3(2-3)$ & 0.031 \\
12 h after blockade & $2(2-2)$ & $2(2-3)$ & 0.017 \\
24 h after blockade & $2(2-2)$ & $2(2-2)$ & 0.545 \\
48 h after blockade & $2(2-2)$ & $2(2-2)$ & 0.724 \\
\hline
\end{tabular}

Values are expressed as the median (interquartile range). Groups: M, patients received an epidural injection of $0.75 \%$ ropivacaine $(12 \mathrm{ml})$ and morphine $(2 \mathrm{mg}$ ) for surgical anesthesia, and epidural infusion of morphine $(2 \mathrm{mg})$ in $100 \mathrm{ml} 0.2 \%$ ropivacaine at $2 \mathrm{ml} / \mathrm{h}$ for $48-\mathrm{h}$ post-operative analgesia; DM, patients received an epidural injection of $0.75 \%$ ropivacaine $(12 \mathrm{ml})$ and morphine $(2 \mathrm{mg})$ combined with dexmedetomidine $(0.5 \mu \mathrm{g} / \mathrm{kg})$ for surgical anesthesia, and epidural infusion of morphine $(2 \mathrm{mg})$ and dexmedetomidine $(200 \mu \mathrm{g})$ in $100 \mathrm{ml} 0.2 \%$ ropivacaine at $2 \mathrm{ml} / \mathrm{h}$ for 48 -h post-operative analgesia.

for pain relief following cesarean section. These side effects, particularly respiratory depression, are dose-dependent (21). To reduce these side effects and improve analgesic quality, the analgesic technique commonly applied at Jining No. 1 People's Hospital (Jining, China) is the administration of epidural morphine $(2 \mathrm{mg})$ at the end of surgery, followed by PCEA with ropivacaine $(200 \mathrm{mg})$ and morphine $(2 \mathrm{mg})$ in $100 \mathrm{ml}$ saline at a rate of $2 \mathrm{ml} / \mathrm{h}$ for $48 \mathrm{~h}$. In the present study, epidural morphine was administered at $3 \mathrm{~min}$ after injection of the test dose, not at the end of surgery.

Dexmedetomidine has previously been administered as an adjuvant in epidural anesthesia in various populations, including pregnant females $(1,22-26)$. These studies demonstrated that epidural dexmedetomidine may shorten the onset time of sensory and motor blockade, prolong the blockade durations and decrease the requirement for rescue analgesia $(1,22-26)$. The epidural dose of dexmedetomidine ranged between 0.5 and $1.5 \mu \mathrm{g} / \mathrm{kg}$ in these previous studies $(1,22-26)$. Hypotension is the most common complication occurring with neuroaxial blockade. It is known that dexmedetomidine may cause dose-dependent hypotension and bradycardia (27). Dexmedetomidine may exacerbate the risk of maternal hypotension when epidurally administered. Dexmedetomidine $(0.5 \mu \mathrm{g} / \mathrm{kg})$ added to neuraxial anesthesia has been demonstrated to not be associated with hypotension and bradycardia $(1,22-24)$. Therefore, a relatively low dose of dexmedetomidine $(0.5 \mu \mathrm{g} / \mathrm{kg})$ was used as an adjuvant to epidural anesthesia in the present study. Patients receiving epidural dexmedetomidine $(0.1 \mu \mathrm{g} / \mathrm{kg})$ as a loading dose and a continuous infusion of $0.15 \%$ ropivacaine at $2 \mathrm{ml} / \mathrm{h}$ combined with dexmedetomidine $(1 \mu \mathrm{g} / \mathrm{kg}$ in $100 \mathrm{ml}$ of $0.15 \%$ ropivacaine) following cesarean section under epidural anesthesia reported insufficient analgesia, with a VAS score $>3$, whether at rest or while coughing, at 12 and $24 \mathrm{~h}$ after surgery (8). Sufficient pain relief was attained in patients undergoing abdominal cancer surgery who received a bolus dose of
Table IV. Adverse events during and after surgery (incidence; score).

\begin{tabular}{lccc}
\hline Item & $\begin{array}{c}\text { Group M } \\
(\mathrm{n}=40)\end{array}$ & $\begin{array}{c}\text { Group DM } \\
(\mathrm{n}=40)\end{array}$ & P-value \\
\hline $\begin{array}{l}\text { Hypotension } \\
\text { Intra }\end{array}$ & $5(12.5)$ & $12(30.0)$ & 0.056 \\
Post & $0(0)$ & $2(5.0)$ & 0.474 \\
Bradycardia & & & \\
Intra & $0(0)$ & $0(0)$ & 1.000 \\
Post & $0(0)$ & $0(0)$ & 1.000
\end{tabular}

Nausea

Intra $\quad 0(0) ; 0(0-0) \quad 1(2.5) ; 0(0-0) \quad 1.000 ; 0.317$

Post $\quad 5(12.5) ; 0(0-0) 13(32.5) ; 0(0-2) \quad 0.032 ; 0.042$

Vomiting

Intra $\quad 0(0) ; 0(0-0) \quad 0(0) ; 0(0-0) \quad 1.000 ; 1.000$

Post $\quad 10(25) ; 0(0-0) 15(37.5) ; 0(0-1) 0.228 ; 0.267$

$\begin{array}{llll}\text { PONV } & 12(30) & 18(45) & 0.165\end{array}$

Pruritus

Intra $\quad 0(0) ; 0(0-0) \quad 1(2.5) ; 0(0-0) \quad 1.000 ; 0.317$

Post $18(45) ; 0(0-2) 17(42.5) ; 0(0-2) \quad 0.822 ; 0.781$

Dizziness

Intra $\quad 2(5.0) ; 0(0-0) \quad 2(5.0) ; 0(0-0) \quad 1.000 ; 0.980$

Post $\quad 0 ; 0(0-0) \quad 2(5.0) ; 0(0-0) \quad 0.474 ; 0.155$

Shivering

Intra $\quad 1(2.5) ; 0(0-0) \quad 0(0) ; 0(0-0) \quad 1.000 ; 0.317$

Post $\quad 0(0) ; 0(0-0) \quad 0(0) ; 0(0-0) \quad 1.000 ; 1.000$

Incidence is expressed as $\mathrm{n}(\%)$ and the score as the median (interquartile range). Groups: $M$, patients received an epidural injection of $0.75 \%$ ropivacaine $(12 \mathrm{ml})$ and morphine $(2 \mathrm{mg})$ for surgical anesthesia, and epidural infusion of morphine $(2 \mathrm{mg})$ in $100 \mathrm{ml} \mathrm{0.2 \%}$ ropivacaine at $2 \mathrm{ml} / \mathrm{h}$ for 48 -h post-operative analgesia; DM, patients received an epidural injection of $0.75 \%$ ropivacaine $(12 \mathrm{ml})$ and morphine $(2 \mathrm{mg})$ combined with dexmedetomidine $(0.5 \mu \mathrm{g} / \mathrm{kg})$ for surgical anesthesia, and epidural infusion of morphine $(2 \mathrm{mg})$ and dexmedetomidine $(200 \mu \mathrm{g})$ in $100 \mathrm{ml} 0.2 \%$ ropivacaine at $2 \mathrm{ml} / \mathrm{h}$ for 48 -h post-operative analgesia. PONV, post-operative nausea and vomiting; intra, intra-operative; post, post-operative.

$6 \mathrm{ml}$ of $0.1 \%$ bupivacaine plus $0.5 \mu \mathrm{g} / \mathrm{ml}$ dex medetomidine, followed by a continuous epidural infusion of $6 \mathrm{ml} / \mathrm{h}$ of $0.1 \%$ bupivacaine plus $0.5 \mu \mathrm{g} / \mathrm{ml}$ dexmedetomidine throughout the surgical period, continued for $48 \mathrm{~h}$ post-operatively (28). Zhang and $\mathrm{Li}$ (9) reported that the optimal dose of dexmedetomidine is $4 \mu \mathrm{g}$ in $0.1 \%$ ropivacaine $(8 \mathrm{ml})$ as a loading dose, and an hourly infusion dose for epidural labor analgesia. Therefore, $2 \mu \mathrm{g} / \mathrm{ml}$ dexmedetomidine was added to the epidural analgesia formulation in the present study.

Epidural morphine results in potent and prolonged analgesic effects via binding with the opioid receptor at the spinal cord dorsal horn (29). The analgesic mechanism of dexmedetomidine differs from that of morphine. Dexmedetomidine directly acts on $\alpha 2$ adrenergic receptors on the pre- and post-synaptic membranes of spinal cord 
Table V. Data on post-operative analgesia.

\begin{tabular}{|c|c|c|c|}
\hline Item & $\begin{array}{l}\text { Group M } \\
(\mathrm{n}=40)\end{array}$ & $\begin{array}{l}\text { Group DM } \\
\quad(n=40)\end{array}$ & P-value \\
\hline \multicolumn{4}{|l|}{ NRS score at rest } \\
\hline $4 \mathrm{~h}$ after blockade & $0(0-0)$ & $0(0-0)$ & 0.569 \\
\hline $12 \mathrm{~h}$ after blockade & $0(0-0)$ & $0(0-0)$ & 0.699 \\
\hline $24 \mathrm{~h}$ after blockade & $2(1-3)$ & $2(0-3)$ & 0.757 \\
\hline $48 \mathrm{~h}$ after blockade & $0(0-3)$ & $0(0-3)$ & 0.667 \\
\hline \multicolumn{4}{|c|}{ NRS score upon movement } \\
\hline $4 \mathrm{~h}$ after blockade & $0(0-0)$ & $0(0-0)$ & 0.747 \\
\hline $12 \mathrm{~h}$ after blockade & $2(2-3)$ & $2(0-3)$ & 0.892 \\
\hline $24 \mathrm{~h}$ after blockade & $3(3-5)$ & $3(3-5)$ & 0.758 \\
\hline $48 \mathrm{~h}$ after blockade & $3(2-4)$ & $3(2-3)$ & 0.827 \\
\hline Remedial tramadol & $8(20.0)$ & $10(25.0)$ & 0.592 \\
\hline \multicolumn{4}{|l|}{$\begin{array}{l}\text { Visceral pain caused by } \\
\text { uterine contraction }\end{array}$} \\
\hline Cases & $27(67.5)$ & $15(37.5)$ & 0.007 \\
\hline NRS scores & $4.5(0-7)$ & $0(0-6)$ & 0.023 \\
\hline \multicolumn{4}{|c|}{$\begin{array}{l}\text { Values are expressed as the median (interquartile range) or } \mathrm{n}(\%) \text {. } \\
\text { Groups: } \mathrm{M} \text {, patients received an epidural injection of } 0.75 \% \text { ropi- } \\
\text { vacaine }(12 \mathrm{ml}) \text { and morphine }(2 \mathrm{mg}) \text { for surgical anesthesia, and } \\
\text { epidural infusion of morphine }(2 \mathrm{mg}) \text { in } 100 \mathrm{ml} 0.2 \% \text { ropivacaine at } \\
2 \mathrm{ml} / \mathrm{h} \text { for } 48 \text {-h post-operative analgesia; } \mathrm{DM} \text {, patients received an } \\
\text { epidural injection of } 0.75 \% \text { ropivacaine }(12 \mathrm{ml}) \text { and morphine }(2 \mathrm{mg}) \\
\text { combined with dexmedetomidine }(0.5 \mu \mathrm{g} / \mathrm{kg}) \text { for surgical anesthesia, } \\
\text { and epidural infusion of morphine }(2 \mathrm{mg}) \text { and dexmedetomidine } \\
(200 \mu \mathrm{g}) \text { in } 100 \mathrm{ml} 0.2 \% \text { ropivacaine at } 2 \mathrm{ml} / \mathrm{h} \text { for } 48 \text {-h post-operative } \\
\text { analgesia. NRS, numeric rating scale. }\end{array}$} \\
\hline
\end{tabular}

neurons, hyperpolarizing the neuron membrane potentials via G-protein-mediated activation of $\mathrm{K}^{+}$, decreasing sympathetic outflow and norepinephrine release, thus inhibiting the transmission of nociceptive information $(7,30)$. Therefore, the combination of these drugs theoretically produces a synergistic analgesic effect. The present results indicated that supplementation of dexmedetomidine in addition to epidural morphine and ropivacaine enhanced the anesthetic effect, as indicated by more complete motor blockade at 20 min post-injection and fewer cases of visceral pain caused by peritoneal traction or uterine contraction. The mechanism of how epidural dexmedetomidine improves motor blockade and alleviates visceral pain remains elusive. It may also exert its effects through hyperpolarizing the spinal cord neuron membrane potentials via G-protein-mediated activation of $\mathrm{K}^{+}$. Drugs including oxytocin and misoprostol for uterine contraction are routinely used for two consecutive post-delivery days to promote rapid uterine involution at Jining No. 1 People's Hospital (Jining, China). The effect of dexmedetomidine on visceral pain has also been demonstrated with epidural administration for labor analgesia (12) and with intrathecal administration for cesarean section (31). The similar sensory level at 20 min post-injection indicated that the addition of epidural dexmedetomidine may not affect the cephalad spread of ropivacaine, which was partly supported by Yousef et al (1) and Hanoura et al (2), who
Table VI. Neonatal Apgar scores, umbilical blood gas analysis and NACS sore.

\begin{tabular}{|c|c|c|c|}
\hline Item & $\begin{array}{l}\text { Group M } \\
(\mathrm{n}=40)\end{array}$ & $\begin{array}{l}\text { Group DM } \\
\quad(n=39)\end{array}$ & P-value \\
\hline \multicolumn{4}{|l|}{ Apgar scores } \\
\hline At $1 \mathrm{~min}$ & $10(9-10)$ & $10(9-10)$ & 0.461 \\
\hline At $5 \mathrm{~min}$ & $10(10-10)$ & $10(10-10)$ & 0.559 \\
\hline \multicolumn{4}{|l|}{ Umbilical vein } \\
\hline $\mathrm{pH}$ & $7.31 \pm 0.06$ & $7.30 \pm 0.04$ & 0.383 \\
\hline $\mathrm{pCO}_{2}(\mathrm{mmHg})$ & $43.5 \pm 4.8$ & $44.3 \pm 4.6$ & 0.449 \\
\hline $\mathrm{pO}_{2}(\mathrm{mmHg})$ & $27.8 \pm 6.4$ & $29.7 \pm 7.8$ & 0.237 \\
\hline Base excess (mmol/l) & $-2.4 \pm 1.8$ & $-2.6 \pm 2.1$ & 0.649 \\
\hline \multicolumn{4}{|l|}{ Umbilical artery } \\
\hline $\mathrm{pH}$ & $7.28 \pm 0.04$ & $7.28 \pm 0.05$ & 0.844 \\
\hline $\mathrm{pCO}_{2}(\mathrm{mmHg})$ & $49.1 \pm 5.7$ & $48.3 \pm 6.0$ & 0.543 \\
\hline $\mathrm{pO}_{2}(\mathrm{mmHg})$ & $17.9 \pm 5.2$ & $18.6 \pm 5.3$ & 0.553 \\
\hline Base excess (mmol/l) & $-2.2 \pm 2.3$ & $-2.3 \pm 1.9$ & 0.832 \\
\hline NACS at $24 \mathrm{~h}$ after delivery & $38.1 \pm 1.3$ & $38.1 \pm 1.3$ & 0.945 \\
\hline
\end{tabular}

Values are expressed as the median (interquartile range) or the mean \pm SD. Groups: $M$, patients received an epidural injection of $0.75 \%$ ropivacaine $(12 \mathrm{ml})$ and morphine $(2 \mathrm{mg})$ for surgical anesthesia, and epidural infusion of morphine $(2 \mathrm{mg})$ in $100 \mathrm{ml} 0.2 \%$ ropivacaine at $2 \mathrm{ml} / \mathrm{h}$ for 48 -h post-operative analgesia; DM, patients received an epidural injection of $0.75 \%$ ropivacaine $(12 \mathrm{ml})$ and morphine $(2 \mathrm{mg})$ combined with dexmedetomidine $(0.5 \mu \mathrm{g} / \mathrm{kg})$ for surgical anesthesia, and epidural infusion of morphine $(2 \mathrm{mg})$ and dexmedetomidine $(200 \mu \mathrm{g})$ in $100 \mathrm{ml} 0.2 \%$ ropivacaine at $2 \mathrm{ml} / \mathrm{h}$ for 48 -h post-operative analgesia. NACS, neonatal adaptive and capacity score; $\mathrm{pCO}_{2}$, partial pressure of carbon dioxide; $\mathrm{pO}_{2}$, partial pressure of oxygen.

reported that epidural dexmedetomidine did not significantly reduce the time to onset of sensory and motor blockade, the time to reach the highest level of sensory block or the time to readiness for surgery, when combined with intrathecal bupivacaine, epidural bupivacaine and fentanyl.

In the present study, no association was indicated between the incidence and severity of various adverse events and the administration of epidural dexmedetomidine, except post-operative nausea. PONV in patients receiving epidural morphine is naturally considered to be a side effect of morphine. However, the administered dose of epidural morphine was the same in the two groups. A possible explanation may be the potential risk of hypotension associated with epidural dexmedetomidine. Hypotension is another known contributor to PONV. The potential risk of hypotension was indicated by the greater infusion volume and higher incidence of hypotension during surgery in patients receiving dexmedetomidine as an adjuvant to epidural morphine and ropivacaine. In these patients, the occurrence of hypotension is possible during the post-operative analgesia period, but was not noted as an endpoint, which is a limitation of the present study. Dexmedetomidine as an adjuvant to epidural morphine and ropivacaine achieved better sedation during surgery and in the following $12 \mathrm{~h}$ after surgery. This differed from the results of the study 
by Yousef et al (1), in which dexmedetomidine $(0.5 \mu \mathrm{g} / \mathrm{kg})$ was used for cesarean section as an adjuvant to epidural bupivacaine and fentanyl. Morphine causes sedation due to directly activating the opioid receptor or via modulating the binding affinity of gamma-aminobutyric acid for its receptors in various brain regions (32). An analgesic dose of epidural morphine ( $3 \mathrm{mg}$ ) may produce latent sedation for $3 \mathrm{~h}$ using regional anesthesia (33). Dexmedetomidine also results in a dose-dependent sedative and hypnotic effect via inhibiting noradrenergic neurons and disinhibiting gamma-aminobutyric acid neurons at the locus coeruleus in the medulla, thus activating endogenous non-rapid eye movement sleep-promoting pathways (34). The combined use of epidural dexmedetomidine and morphine may lead to a synergistic sedative effect.

Epidural morphine has previously been indicated to not be associated with neonatal outcome (35). Previous studies have also suggested that epidural dexmedetomidine has no adverse effects on neonates $(1,2,9-12)$. Similar results were obtained in the present study with co-administration of epidural dexmedetomidine and morphine. The results suggested no difference in Apgar score, umbilical venous and arterial $\mathrm{pH}, \mathrm{pCO}_{2}, \mathrm{pO}_{2}$ and base excess values, as well as NACS score, between the M and DM groups. The lack of any symptoms or signs of neurological deficit reported by the new mothers suggested that epidural dexmedetomidine was safe when added to epidural morphine. The safety of epidural dexmedetomidine has been demonstrated in several previous studies $(36,37)$.

The present study has various limitations. First, epidural morphine alone at a relatively low dose is not adequate for post-cesarean analgesia, as demonstrated in a previous study (20). However, improved efficacy of post-operative analgesia is attained by the combination of epidural morphine and local anesthetic, as demonstrated in several studies $(3,4)$. The anti-nociceptive effect of epidural dexmedetomidine as an adjuvant to continuous morphine and local anesthetic for post-cesarean analgesia remains to be fully uncovered, as indicated by the results of similar NRS scores at rest and upon movement in the present study. Capogna et al (13) suggested that the addition of clonidine to epidural morphine and bupivacaine delayed the time to repeat epidural administration of morphine and bupivacaine, and reduced the requirement for repeated administration for post-cesarean analgesia. Furthermore, remedial sufentanil was intra-operatively administered to alleviate visceral pain, which may be associated with post-operative opioid-associated adverse effects. In addition, the possible adverse effects of each drug must be kept in mind. Respiratory depression was not assessed in the present study. In a previous study, $50 \%$ of females who received epidural morphine ( $3 \mathrm{mg}$ ) experienced respiratory depression, but the severity was mild and none of the patients required treatment (38). It is not well known whether a synergistic effect on respiration exists with the combination of epidural dexmedetomidine and morphine. Epidural dexmedetomidine has been demonstrated to have a minimal effect on respiration in children (39).

In conclusion, the present study demonstrated that epidural dexmedetomidine reduces intra-operative and post-operative visceral pain and produces better sedation during surgery and following delivery, without any marked influence on morphine-associated side effects and post-operative analgesia, in females undergoing elective cesarean section under epidural anesthesia with morphine and ropivacaine. Due to the potential risk of hypotension, it is necessary to balance the benefit-risk ratio when dexmedetomidine is added to epidural morphine and ropivacaine for cesarean section and subsequent pain relief.

\section{Acknowledgements}

Not applicable.

\section{Funding}

No funding was received.

\section{Availability of data and materials}

The datasets generated and/or analyzed during the present study are available in the Chinese Clinical Registry Center (http://www.chictr.org.cn; Registration number, ChiCTR1900027942).

\section{Authors' contributions}

YY contributed to the conception and design of the study, data acquisition and writing of the manuscript. CJS contributed to the data acquisition, writing and revising of the manuscript. CWS contributed to the design of the study, data acquisition and writing of the manuscript. CL contributed to the conception and design of the study, data acquisition and analysis and revising of the manuscript. All authors read and approved the final manuscript.

\section{Ethics approval and consent to participate}

The present study was approved by the Jining No. 1 People's Hospital Ethics Committee for Human Studies (approval no. 2018-003) and written informed consent was obtained from all patients.

\section{Patient consent for publication}

Not applicable.

\section{Competing interests}

The authors declare that they have no competing interests.

\section{References}

1. Yousef AA, Salem HA and Moustafa MZ: Effect of mini-dose epidural dexmedetomidine in elective cesarean section using combined spinal-epidural anesthesia: A randomized double-blinded controlled study. J Anesth 29: 708-714, 2015.

2. Hanoura SE, Hassanin R and Singh R: Intraoperative conditions and quality of postoperative analgesia after adding dexmedetomidine to epidural bupivacaine and fentanyl in elective cesarean section using combined spinal-epidural anesthesia. Anesth Essays Res 7: 168-172, 2013.

3. Sun J, Wu X, Xu X, Jin L, Han N and Zhou R: A comparison of epidural magnesium and/or morphine with bupivacaine for postoperative analgesia after cesarean section. Int J Obstet Anesth 21: 310-316, 2012. 
4. Agarwal K, Agarwal N, Agrawal VK, Agarwal A and Sharma M: Efficacy of single dose epidural morphine versus intermittent low-dose epidural morphine along with bupivacaine for postcaesarean section analgesia. Anesth Essays Res 6: 25-28, 2012.

5. Bonnet MP, Mignon A, Mazoit JX, Ozier Y and Marret E: Analgesic efficacy and adverse effects of epidural morphine compared to parenteral opioids after elective caesarean section: A systematic review. Eur J Pain 14: 894.e1-e9, 2010.

6. Bhana N, Goa KL and McClellan KJ: Dexmedetomidine. Drugs 59: 263-268, 2000

7. Zhang X, Wang D, Shi M and Luo Y: Efficacy and safety of dexmedetomidine as an adjuvant in epidural analgesia and anesthesia: A systematic review and meta-analysis of randomized controlled trials. Clin Drug Investig 37: 343-354, 2017.

8. Mo Y and Qiu S: Effects of dexmedetomidine in reducing post-cesarean adverse reactions. Exp Ther Med 14: 2036-2039, 2017.

9. Zhang W and Li C: EC50 of epidural ropivacaine combined with dexmedetomidine for labor analgesia. Clin J Pain 34: 950-953, 2018.

10. Wangping $\mathrm{Z}$ and Ming R: Optimal dose of epidural dexmedetomidine added to ropivacaine for epidural labor analgesia: A pilot study. Evid Based Complement Alternat Med 2017: 7924148, 2017.

11. Zhao Y, Xin Y, Liu Y, Yi X and Liu Y: Effect of epidural dexmedetomidine combined with ropivacaine in labor analgesia: A randomized double-blinded controlled study. Clin J Pain 33: 319-324, 2017.

12. Selim MF,Elnabtity AM and Hasan AM: Comparative evaluation of epidural bupivacaine-dexmedetomidine and bupivacaine-fentanyl on Doppler velocimetry of uterine and umbilical arteries during labor. J Prenat Med 6: 47-54, 2012.

13. Capogna G, Celleno D, Zangrillo A, Costantino P and Foresta S: Addition of clonidine to epidural morphine enhances postoperative analgesia after cesarean delivery. Reg Anesth 20: 57-61, 1995.

14. Bromage PR: A comparison of the hydrochloride and carbon dioxide salts of lidocaine and prilocaine in epidural analgesia. Acta Anaesthesiol Scand Suppl 16: 55-69, 1965.

15. Ramsay MA, Savege TM, Simpson BR and Goodwin R: Controlled sedation with alphaxalone-alphadolone. Br Med J 2: 656-659, 1974.

16. Sankar-Maharaj S, Chen D and Hariharan S: Postoperative shivering among cannabis users at a public hospital in trinidad, west indies. J Perianesth Nurs 33: 37-44, 2018.

17. Hashemi SJ, Jabalameli M and Mokhtary F: Effects of different anesthetic techniques on neurologic and adaptation capacity in newborn with elective cesarean section. Adv Biomed Res 4: 249, 2015.

18. O'Neill P, Duarte F, Ribeiro I, Centeno MJ and Moreira J: Ropivacaine continuous wound infusion versus epidural morphine for postoperative analgesia after cesarean delivery: A randomized controlled trial. Anesth Analg 114: 179-185, 2012.

19. Palmer CM, Emerson S, Volgoropolous D and Alves D: Dose-response relationship of intrathecal morphine for postcesarean analgesia. Anesthesiology 90: 437-444, 1999.

20. Singh SI, Rehou S, Marmai KL and Jones PM: The efficacy of 2 doses of epidural morphine for postcesarean delivery analgesia: A randomized noninferiority trial. Anesth Analg 117: 677-685, 2013.

21. Fuller JG, McMorland GH, Douglas MJ and Palmer L: Epidural morphine for analgesia after caesarean section: A report of 4880 patients. Can J Anaesth 37: 636-640, 1990.

22. Zeng XZ, Xu YM, Cui XG, Guo YP and Li WZ: Low-dose epidural dexmedetomidine improves thoracic epidural anaesthesia for nephrectomy. Anaesth Intensive Care 42: 185-190, 2014.

23. Karhade SS, Acharya SA and Harnagale K: Comparative analysis of epidural bupivacaine versus bupivacaine with dexmedetomidine for vaginal hysterectomy. Anesth Essays Res 9: 310-313, 2015.
24. Sathyanarayana LA, Heggeri VM, Simha PP, Narasimaiah S, Narasimaiah $M$ and Subbarao BK: Comparison of epidural bupivacaine, levobupivacaine and dexmedetomidine in patients undergoing vascular surgery. J Clin Diagn Res 10: UC13-UC17, 2016.

25. Kaur S, Atti JP, Kaur G and Singh TP: Comparative evaluation of ropivacaine versus dexmedetomidine and ropivacaine in epidural anesthesia in lower limb orthopedic surgeries. Saudi J Anaesth 8: 463-469, 2014

26. Soni P: Comparative study for better adjuvant with ropivacaine in epidural anesthesia. Anesth Essays Res 10: 218-222, 2016.

27. Ebert TJ, Hall JE, Barney JA, Uhrich TD and Colinco MD: The effects of increasing plasma concentrations of dexmedetomidine in humans. Anesthesiology 93: 382-394, 2000.

28. Hetta DF, Fares KM, Abedalmohsen AM, Abdel-Wahab AH, Elfadl GMA and Ali WN: Epidural dexmedetomidine infusion for perioperative analgesia in patients undergoing abdominal cancer surgery: Randomized trial. J Pain Res 11: 2675-2685, 2018.

29. Bujedo BM: Spinal opioid bioavailability in postoperative pain. Pain Pract 14: 350-364, 2014

30. Ishii H, Kohno T, Yamakura T, Ikoma M and Baba H: Action of dexmedetomidine on the substantia gelatinosa neurons of the rat spinal cord. Eur J Neurosci 27: 3182-3190, 2008.

31. Bi YH, Cui XG, Zhang RQ, Song CY and Zhang YZ: Low dose of dexmedetomidine as an adjuvant to bupivacaine in cesarean surgery provides better intraoperative somato-visceral sensory block characteristics and postoperative analgesia. Oncotarget 8: 63587-63595, 2017.

32. Corrigan F, Wu Y, Tuke J, Coller JK, Rice KC, Diener KR, Hayball JD, Watkins LR, Somogyi AA and Hutchinson MR: Alcohol-induced sedation and synergistic interactions between alcohol and morphine: A key mechanistic role for Toll-like receptors and MyD88-dependent signaling. Brain Behav Immun 45: 245-252, 2015

33. Hannallah MS and Mundt DJ: Effect of epidural morphine on sedation requirements during regional anesthesia. J Clin Anesth 6: 10-13, 1994.

34. Nelson LE, Lu J, Guo T, Saper CB, Franks NP and Maze M: The alpha2-adrenoceptor agonist dexmedetomidine converges on an endogenous sleep-promoting pathway to exert its sedative effects. Anesthesiology 98: 428-436, 2003.

35. Hughes SC, Rosen MA, Shnider SM, Abboud TK, Stefani SJ and Norton M: Maternal and neonatal effects of epidural morphine for labor and delivery. Anesth Analg 63: 319-324, 1984.

36. Zeng XZ, Lu ZF, Lv XQ, Guo YP and Cui XG: Epidural Co-administration of dexmedetomidine and levobupivacaine improves the gastrointestinal motility function after colonic resection in comparison to Co-administration of morphine and levobupivacaine. PLoS One 11: e0146215, 2016.

37. Zeng X, Jiang J, Yang L and Ding W: Epidural dexmedetomidine reduces the requirement of propofol during total intravenous anaesthesia and improves analgesia after surgery in patients undergoing open thoracic surgery. Sci Rep 7: 3992, 2017.

38. Terada S, Irikoma S, Yamashita A and Murakoshi T: Incidence of respiratory depression after epidural administration of morphine for cesarean delivery: Findings using a continuous respiratory rate monitoring system. Int J Obstet Anesth 38: 32-36, 2019.

39. Trifa M, Tumin D and Tobias JD: Dexmedetomidine as an adjunct for caudal anesthesia and analgesia in children. Minerva Anestesiol 84: 836-847, 2018.

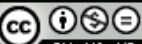

This work is licensed under a Creative Commons Attribution-NonCommercial-NoDerivatives 4.0 International (CC BY-NC-ND 4.0) License. 